\title{
Electrospun Fibers in Composite Materials for Medical Applications
}

\author{
A.C. Baptista, I. Ferreira and J.P. Borges \\ CENIMAT/I3N, Departamento de Ciência dos Materiais, Faculdade de Ciências e Tecnologia, FCT, \\ Universidade Nova de Lisboa 2829 - 516 Caparica, Portugal
}

\begin{abstract}
The development of nanoscaled materials has deserved a remarkable interest for biomedical applications. Biological tissues are essentially composite materials with particular mechanical properties that should be carefully considered during the design of innovative biomedical scaffolds. Electrospun membranes are often found in medical applications due to its high specific surface which creates a 3D porous structure that mimics the native extracellular matrix. These electrospun membranes can also be designed to have enhanced mechanical properties, biocompatibility and cellular response making them appealing and inspiring to be used in composites materials.

This paper reviews the new insights in the development of advanced nanostructured composites materials based on electrospun fibers. From tissue engineering to bioelectronics, these composite materials can be found in the most promising research developments for the medical applications.
\end{abstract}

Keywords: Bioelectronics, composite materials, drug delivery systems, electrospun fibers, tissue engineering.

\section{INTRODUCTION}

Advances in nanotechnology gave the possibility of tailoring the material structures at the nanometer scale. Nanomaterials have similar sizes to that of most biological molecules and structures. Consequently, they are useful for both in vivo and in vitro biomedical applications [1]. The integration of nanomaterials with biology has led to the development of innovative diagnostic devices, analytical tools, physical therapy applications and drug delivery vehicles [2]

In the following section this paper reviews the techniques used for nanofibers production giving special attention to electrospinning. Considering medical applications, an overview about electrospun fibers is given foreseeing the developments of composites materials with improved properties.

\section{NANOFIBERS}

Nanofibers are nanostructures that have at least one dimension in the nanometer scale. Being a twodimensional nanomaterial, nanofibers normally have their diameters between tens and hundreds of nanometers. Due to the low diameter size, they have high specific surface area, which is an attractive physical characteristic for a wide range of applications. For that reason they also exhibit new or enhanced sizedependent properties when compared with larger structures of the same material [3].

\footnotetext{
*Address correspondence to this author at the CENIMAT/I3N, Departamento de Ciência dos Materiais, Faculdade de Ciências e Tecnologia, FCT, Universidade Nova de Lisboa 2829 - 516 Caparica, Portugal; Tel: +351 21 2948564; Fax: +35121 2957810; E-mail: jpb@fct.unl.pt
}

Several methods such as drawing [4], phaseseparation [5], template [6], self-assembly [7] and electrospinning [8] have been used to fabricate nanofibers. The drawing process makes a single fiber at each time using a sharp tip. For instance, the tip of an atomic force microscope (AFM) can be used to pull a fiber from a droplet of a viscoelastic solution by applying a voltage [4]. This process is possible only with viscoelastic materials that undergo strong deformations while being cohesive enough to support the stresses developed during the drawing. The phase separation method consists in mixing the polymer and the solvent before gelation. After phase separation, the solvent is removed by drying and a porous nanofibrous structure is created [5]. However, the whole process takes relatively long time. For the template synthesis, a nanoporous membrane is used as a template to make nanofibers with controlled shape and diameter [6]. This method allows the use of electronically conducting polymers, metals, carbon-based materials and semiconductors as raw materials. An additional process is the self-assembly in which individual preexisting components organize themselves into desired patterns and functions [7]. The intermolecular forces are the main mechanism responsible for the assembling of molecule units that determine the shape of nanofibers. Similarly to the phase separation process, self-assembly is a time-consuming process for the production of continuous polymer nanofibers. The usefulness of these methods is restricted by a limited number of material combinations, high costs and low production rates. In contrast, electrospinning is perhaps the simplest process for producing nanofibers with relatively high productivity. Electrospinning is a broadly 
used technology that uses an electrical field to create a charged jet of a polymer solution [9]. In a conventional setup, a polymer solution passes through a capillary and a high voltage is applied such that the particles within the solution are charged creating a repulsive force. At a critical voltage, the repulsive force overcomes the surface tension of the solution and a jet erupts from the tip of the capillary towards a grounded collector. There are a wide range of polymers and precursors that can be electrospun such as PLA [9], polyurethanes [10], silk fibroin [11], collagen [12], cellulose and its derivatives [13, 14], composites [15], and ceramics [16]. The electrospinning is then a versatile and inexpensive way to produce nanofibers with controllable sizes and properties.

The electrospinning also enables the production highly porous 3D structures having large surface to volume ratios with suitable physical and chemical properties for a wide variety of applications, such as sensors [17], antibacterial surfaces [18], scaffolds [19], photocatalyst [20] and solar energy applications [21] (Figure 1). Moreover, electrospinning has the advantage of combining different materials with singular morphological structures making it a powerful tool to design functional materials, especially for biomedical applications. For instance, conventional or modified electrospinning setups can be used to encapsulate biomolecules or bioactive molecules into fibers [19].

\section{ELECTROSPUN FIBERS IN COMPOSITE MATERIALS}

A composite material is commonly defined as a material composed by two or more phases: a matrix (or a continuous phase) and at least one dispersed phase. The continuous phase is responsible for the structure of the composite (volume) and act as a support for the dispersed material(s). The dispersed phase is typically responsible for enhancing one or more properties of the matrix. Most of the composites are designed to have enhanced mechanical properties, as stiffness and strength, but the improvement of thermal, electrical, density or bioactivity properties should also be considered. The resulting synergism allows the design of materials with properties that are unavailable from the individual constituents [22].

The 3D porous structure of electrospun membranes mimics the native extracellular matrix (ECM). Additionally to its high specific surface, electrospun membranes can be easily designed to have enhanced mechanical properties, biocompatibility and cellular response, making them appealing to be used in composites materials. For that reason, in the following subsections is given a detailed overview of the recent developments using electrospun fibers in composite materials for medical applications.

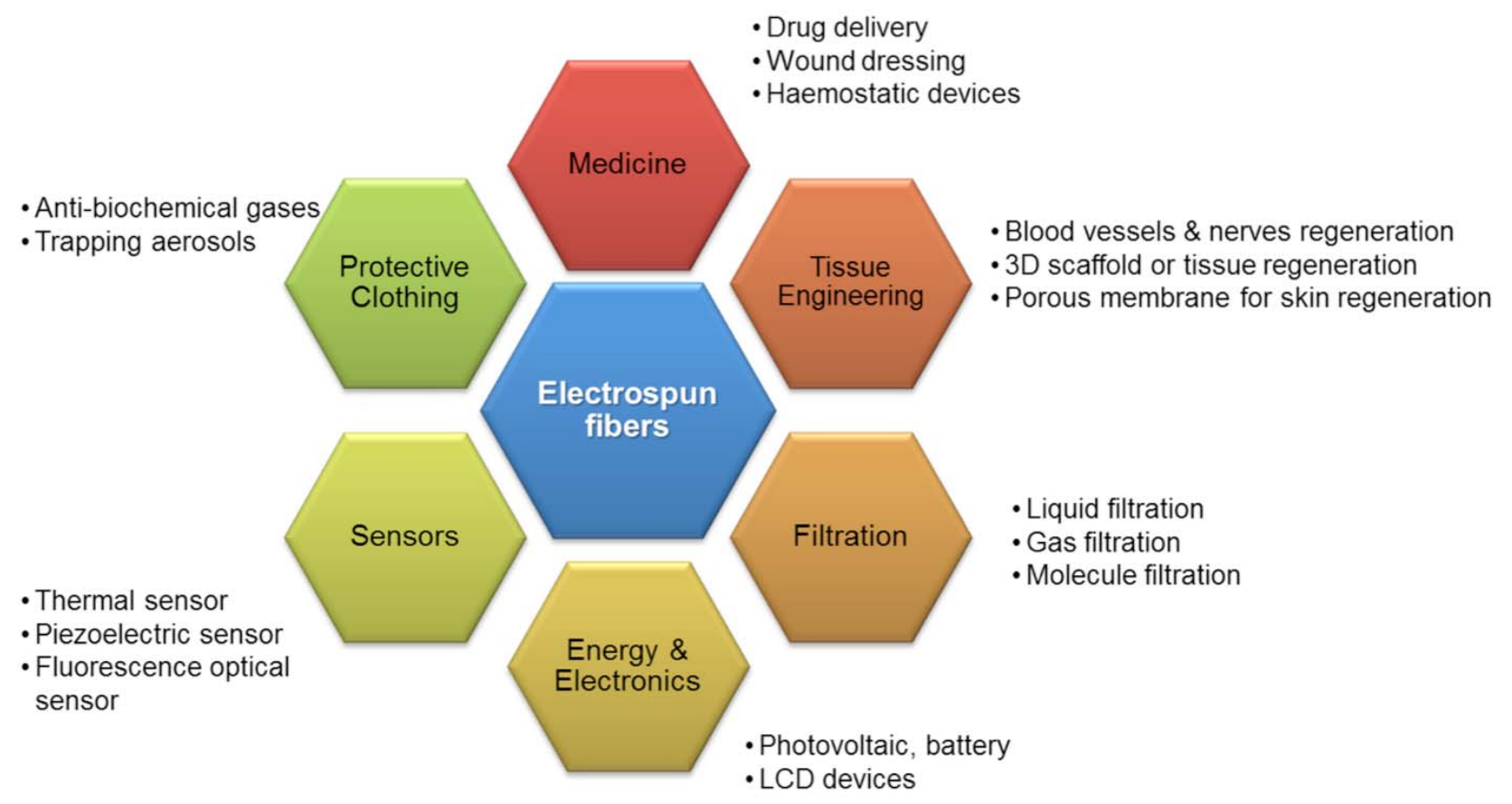

Figure 1: Some applications of electrospun nanofibers. 


\subsection{Tissues Engineering}

Tissue engineering has emerged as an interdisciplinary field that applies the engineering and life science principles to develop biological substitutes for restoring, maintaining or improving the function of human tissues. One of the main challenges in this field is the design and engineering of scaffolds or polymeric matrices that mimic the structure and biological functions of the ECM [3].

A functional scaffold should possess a high degree of porosity with an appropriate pore size distribution and interconnectivity. It is also required that its structural integrity prevents the collapse of scaffold's pores during neo-tissue formation. Furthermore, the scaffold should be nontoxic, biocompatible and interact with the cells to promote adhesion, proliferation, migration and differentiated cell function [23]. Many studies can be found in literature where scaffolds made of electrospun nanofibers have been used for mimicking tissues such as blood vessels [24-26], bones $[27,28]$ and muscles $[29,30]$.

\subsubsection{Blood Vessels}

Tissue engineering of blood vessels is mostly focused on the development of vascular grafts with small diameter (inner diameter $<5 \mathrm{~mm}$ ). The long-term patency of small-diameter vascular grafts is still a challenging issue because of easy restenosis caused by thrombosis and bursting pressure. For that reason, tissue engineering offers an alternative approach to address the need for small-diameter vascular grafts through the design of non-thrombogenic interface [3].

Electrospinning provides the construction of vascular scaffolds due to the simplicity of shaping tubular constructs using rotation and translational motion. Vaz [15] and colleagues have been using a sequential multi-layering electrospinning with a rotating mandrel-type collector to produce scaffolds that mimic morphologically and mechanically the architecture of a blood vessel. It is well known that in the media layer of the native blood vessels, the smooth muscle cells (SMCs) and collagen fibrils have a marked circumferential orientation to provide the mechanical strength necessary to withstand high circulatory pressures [3]. Additionally, the intima layer of the native blood vessels consists in endothelial cells coating the vessels internal surface. Between those two layers exists an internal elastic lamina mainly composed of elastin, which confers elastic properties to the blood vessels. Therefore, a bi-layered tubular scaffold composed by oriented and stiff PLA fibers in the outside and random and elastic PCL fibers in the inside was proposed [15]. The fabricated scaffold showed a desirable level of malleability (elastic up to $10 \%$ strain) and proved to be capable of promoting cell growth and proliferation making it suitable for blood vessel tissue engineering.

The electrospinning of collagen and elastin has also become possible [31]. These two biopolymers are the main structural components of the vascular ECM. Collagen is responsible for the structural integrity and tensile strength of tissues and elastin gives them elasticity. Electrospinning of pure collagen or elastin have showed some limitations due to the poor mechanical properties of the produced fibers. Incorporation of biodegradable synthetic polymers into the structure will impart the scaffolds' strength which will simultaneously maintain a high level of bioactivity due to the presence of the biopolymer (collagen or elastin). Lee [24] has reported the fabrication of a composite vascular scaffolding system by electrospinning polycaprolactone (PCL) and collagen (type I) blends. These composite scaffolds were designed to provide sufficient biomechanical properties and configured to accommodate vascular endothelial and smooth muscle cells for use in vascular tissue engineering applications. Polycaprolactone is an aliphatic polyester that degrades slowly and possesses high tensile and elongation properties for vascular grafts. The resulting composite scaffold showed good biocompatibility and support for cell growth and proliferation in vitro.

The production of electrospun fibers with biomolecules or bioactive molecules such as enzymes, drugs and viruses is possible by using different methods: physical adsorption, blend electrospinning, coaxial electrospinning, or covalent immobilization [3, 19]. The physical adsorption method consists in the attachment of biomolecules to the electrospun membrane via electrostatic forces. This can be achieved through fiber immersion into the solution that contains the biomolecules. In blend electrospinning, the biomolecules are mixed within the polymer solution. The mixed solution is then electrospun to fabricate a hybrid structure. Using the coaxial electrospinning, the polymer solution and the biological one are coaxially and simultaneously electrospun producing composite nanofibers with a core-shell structure. Finally, biomolecules can be immobilized onto the nanofiber surface via chemical bond.

During tissue repair, growth factors induce specific biological responses including cell proliferation and 
migration, matrix synthesis, angiogenesis and release of growth factors. For an appropriate regeneration of small-diameter blood vessels, the proliferation of vascular endothelial cells (VECs) is desirable on the lumen of the graft in the first 7 to 10 days, followed by the growth of vascular smooth muscle cells (VSMCs) on the outer layer which makes the tissue regeneration more stable without thrombosis or burst.

Vascular endothelial growth factors (VEGFs) can stimulate endothelialization and it can also inhibit excessive proliferation of VSMC [32]. Conversely, platelet-derived growth factor has high ability to stimulate VSMCs proliferation [33]. To overcome this problem, different release devices must be designed to control the rapid delivery of VEGF and prolonged release of platelet-derived growth factor-bb (PDGF). For that purpose, two modified coaxial electrospinning techniques were developed by Zhang [26] to encapsulate VEGFs and PDGF, respectively, in order to regulate proliferation of VECs and VSMCs. The double-layered membranes were prepared via coaxial electrospinning of chitosan hydrogel/poly(ethyleneglycol)-b-poly(L-lactide-co-caprolactone) (PELCL) in the inner layer for loading VEGF and methoxy poly(ethylene glycol)-b-poly(L-lactide-co-glycolide) (PELGA) emulsion/PELCL in the outer layer for loading PDGF. PELGA was added to PELCL by emulsion/coaxial electrospinning to slow down the initial release rate of PDGF and accelerate it in the later release period.

These authors have found that dual-release of VEGF and PDGF could effectively accelerate VEC proliferation in the first 6 days and slowly moderate VSMC proliferation in the initial 3 days while generating rapid proliferation after day 6 . In summary, dualdelivery of VEGF and PDGF using the modified electrospun membranes may facilitate revascularization and can bring great benefits for blood vessel regeneration.

\subsubsection{Bones}

Electrospun nanofiber meshes have been studied intensively in bone tissue engineering due to their ability to support cell growth and differentiation into osteogenic phenotypes. A key cellular phenotype is the osteoblast, which is the cell type that lays down the ECM of bone tissue and is thus the target cell type for recruitment and differentiation in bone reconstruction [3].

Synthetic polymers and their copolymers, natural polymers, composites of natural and synthetic polymers, inorganic materials, such as bioactive glass and hydroxyapatite $(\mathrm{HA})$, and composites of inorganic materials with synthetic and natural polymers have been used to produce appropriate nanofiber scaffolds for osseous tissue engineering. A scaffold that maintains stability and promotes cell growth and proliferation but gradually degrades along with the construction of new tissues is required. Ultimately, it should be completely replaced by the new tissue. Prabhakaran [27] have studied the electrospinning fabrication of poly-L-lactide (PLLA), PLLA/HA and PLLA/collagen/HA substrates and its applicability as scaffolds for bone tissue regeneration. Poly-L-lactide is a biodegradable polymer with controlled degradation characteristics that can be used in tissue engineering and drug delivery therapies. Hydroxyapatite is a bioceramic frequently found in biomedical implant applications due to its biodegradability, bioactivity and osteoconductive properties. As a bioceramic, HA cannot be easily shaped in the bone defect sites due to its natural rigidity. However, synthetic biodegradable polymers can improve significantly the mechanical properties of $\mathrm{HA}$. The in vitro assays demonstrated that when HA is introduced in the polymer matrix (PLLA/HA scaffolds) a higher cell proliferation is observed when comparing to PLLA scaffolds. Furthermore, the presence of collagen has accelerated the cell attachment and proliferation on PLLA/collagen/HA scaffolds. Osteoblasts were found to adhere and grow actively on PLLA/collagen/HA nanofibers with mineral deposition 57\% higher than in the PLLA/HA nanofibers. The study concluded that the synergistic effect of the presence of an ECM protein, collagen and HA in a biocomposite scaffold holds great potential for adhesion, proliferation and mineralization of osteoblasts.

In order to develop a bioactive membrane for guided bone regeneration, Wei $\mathrm{Ji}$ [28] has proposed the functionalization of an electrospun membrane with a chemotactic factor.

Guided bone regeneration is typically used as a strategy to heal bony defects in the craniomaxillofacial region. For that purpose, the creation and preservation of an isolated space using a membrane as a barrier to avoid the invasion of fast growing epithelial and other soft tissues into the osseous defect is required. This allows osteogenic cell populations originating from the parent bone to inhabit the osseous defect [34]. These membranes need to be flexible to adapt to a bone defect, preserve the space for bone formation and to attach to soft tissues. On the other hand, 
biodegradability is also a requirement since it avoids surgery in order to remove the membrane. Among the multiple types of progenitor cells located in the bone marrow, bone marrow stromal cells (BMSCs) are considered the most powerful ones during bone regeneration due to its multi-lineage differentiation capacity [35]. In addition, cytokines and chemokines are important factors in mobilization control, trafficking and homing of stem/progenitor cells [36]. Thus, it is essential to increase their local concentration at the target site to induce BMSCs recruitment.

Wei Ji [28] described the preparation of an electrospun membrane of PCL blended with B-type gelatin functionalized with stromal cell derived factor-1 $\alpha$ (SDF-1 $\alpha$ ) by physical adsorption. Among various cytokines or chemokines, SDF-1 $\alpha$ is particularly important in BMSCs homing and localization within the bone marrow. These authors found that $\mathrm{PCL} /$ gelatin electrospun membranes clearly acted as a SDF-1a carrier providing a diffusion-controlled release profile. The bioactive membrane also induced in vitro BMSCs recruitment, demonstrating a great potential for guided bone regeneration.

\subsubsection{Muscles}

Skeletal muscle tissue is composed of bundles of highly oriented and densely packed muscle fibers each with multinucleated cells derived from myoblasts. The fibers are densely packed together in ECM to constitute an organized muscle tissue that generates longitudinal contraction [3]. For muscle tissue reconstruction, scaffolds should allow cellular organization mimicking native individual fiber formation with unidirectional orientation. Electrospun scaffolds should thus have appropriate material characteristics for skeletal muscles: biocompatibility to allow cell adhesion and growth, degradability over time and elasticity to accommodate contractile function.

Similar to what has been done for blood vessels regeneration, Choi [29] studied the feasibility of using $\mathrm{PCL} /$ collagen based nanofibers as a scaffold system for implantable engineered muscles. They investigated how the orientation of electrospun $\mathrm{PCL} /$ collagen nanofibers influences morphology, adhesion, proliferation, differentiation and organization of human skeletal muscle cells. They concluded that unidirectional oriented nanofibers can significantly induce the alignment of muscle cell and myotube formation compared to randomly oriented nanofibers. Aligned nanofiber scaffolds may provide implantable functional muscle tissues for patients with large muscle defects.
It has been reported so far the development of single tissue types. However, there is an increasing demand for complex composite tissue engineering, such as tissue interfaces, possessing coordinated functions [37]. Ladd [30] has proposed the engineering of muscles-tendon junction (MTJ) tissues. One challenge in engineering MTJs is the design of a continuous scaffold suitable for both tissue types. Muscle-tendon junctions require a seamless interface to allow force transfer from muscle to tendon. These authors proposed the fabrication of a dual scaffold which exhibits local mechanical property differences mimicking the trends seen in native MTJs. Coelectrospinning was used to create three distinct scaffold regions: a PCL/collagen region (one end side), a PLLA/collagen region (opposite end side) and an overlap region (center). Both polymers were blended with collagen since it improves cell attachment. The mechanical properties of the three regions were evaluated: the PLLA/collagen side of the scaffold was the stiffest one showing the lowest strain (similar to the tendon); the PCL/collagen side was the most compliant displaying the highest strain (analogous to the muscle); and the middle region possesses an intermediate stiffness and strain levels (similar to the junction). The structure achieved distinct mechanical properties and demonstrated to be an attractive solution for MTJ tissue engineering.

\subsection{Drug Delivery}

Controlled release is an efficient process for delivering drugs in medical therapy. In a controlled release system, the active substance is loaded into a carrier or device and then released at a predictable rate. Exciting developments have been recently made in this field. Due to the high surface area to volume ratio, electrospun nanofibers provide a useful pathway for drug delivery and the release profile can be finely controlled by modulation of nanofiber morphology, porosity and composition [38]. The simplicity of the electrospinning process can also provide the ability to conveniently incorporate therapeutic compounds into the electrospun fibers. The drug can be loaded to the electrospun fibers by several methods such as coating, embedding, and encapsulating by coaxial and emulsion electrospinning [3].

Using the coating method, drug molecules can be adsorbed or cross-linked to the surface of electrospun fibers via a physical or chemical method. Choi [39] has reported the chemically conjugation of a recombinant human epidermal growth factor (rhEGF) with the 
surface of electrospun nanofibers for in vivo wound healing treatment of diabetic ulcers. Current treatments for diabetic foot ulcers include the administration of disinfectants followed by application of epidermal growth factor (EGF)-containing gels around the lesions. This work involved the electrospinning of biocompatibles nanofibers with functional amine groups on the surface (PCL and PCL/poly(ethylene glycol, PEG, block copolymer). Upon immersion in an aqueous solution, the exposed functional amino groups on the surface of the nanofibers were chemically conjugated to rhEGF by activating the carboxylic groups of the protein. Human primary keratinocytes were cultivated on EGF-conjugated nanofibers in order to investigate the effect of EGF nanofibers on the differentiation of keratinocytes. Therefore, wound healing effects of the EGF nanofibers were successfully confirmed in diabetic animals with dorsal wounds.

Another possibility to produce drug-loaded fibers is to electrospun a polymer solution that also contains the therapeutic compound. It is required in this process that the drug solution and polymer solution must be either miscible liquids or that solid drug particles can be well dispersed into the polymer solution. Peng [40] has investigated the use of poly (ethylene glycol)/poly( D, LLactide copolymer electrospun fibers as a drug delivery system. This copolymer is known to have a good biocompatibility in vivo and improved degradation rate. Paracetanol (acetaminophen, N-(4-hydroxy-phenyl) acetamide) was chosen as the model drug since it is widely used as analgesic and antipyretic drug. The drug was mixed with the copolymer solution and electrospun to form the fiber mats. In vitro matrix degradation profiles of these fibers were characterized by measuring their weight loss, the molecular weight decrease and their morphology change. It was observed from these studies that scaffolds with smaller fiber diameter have a higher contact area between polymer and water which, consequently, accelerates the matrix breakdown. In addition, in vitro drug release assays have demonstrated that the release behavior mainly depends on polymer matrix degradation and drug diffusion. In conclusion, the drug release rate can be controlled by polymer degradation which can be tuned by adjusting the electrospun fiber diameter and its porosity.

Since the loading of bioactive drugs into electrospun fibers via embedding method is still a challenge, the electrospun of core-shell and hollow structured fibers come as a solution for the preparation of drug delivery systems for larger molecules [41-43].
The emulsion electrospinning is an attractive approach to encapsulate a drug into a fiber. This process is quite similar to conventional electrospinning except that the solution is replaced with a water-in-oil emulsion [42]. Kai Wei [43] proposed a fluorescein isothiocyanate-dextran (FITC-dextran)/poly(lactic-coglycolic acid) (PLGA) fibrous composite scaffold. Used as a model drug, FITC-dextran was previously dissolved in an aqueous solution and then was emulsified with the PLGA oil phase to prepare the emulsion electrospinning dope. Morphological characterization showed that the inner component FITC-dextran was properly wrapped in the center of PLGA. Moreover, the core-shell structure helped the sustained release of the model drug from the fiber. A burst release profile of $60 \%$ is notorious for the first 2 weeks after which the scaffold exhibited a sustained release profile of approximately $1 \%$ cumulative release per day for 4 weeks long. The developed scaffold has displayed a release profile that might be useful for sitespecific drug-release systems.

\subsection{Bioelectronics}

Bioelectronics combines biology, electronics and nanotechnology sciences. Multifunctional devices can be made by integrating biological materials with electronic elements providing a novel and broad platform for biochemical and biotechnological processes [44]. These functional devices can be used to develop sensing systems, as enzyme-based biosensors [45], DNA-sensors [46], immunosensors [47], and to develop implantable biofuel cells [48] for biomedical applications, self-powered biosensors [45], autonomously operated devices, among others.

\subsubsection{Biosensors}

Biosensors can be described as integrated receptor-transducer devices which provide selective quantitative or semi-quantitative analytical information using biological recognition elements [44]. The main advantages of biosensors over traditional analytical detection techniques are their cost-effectiveness and fast and portable detection, which makes in situ and real time monitoring possible [49].

Enzymes are well-known biological sensing materials used in the development of biosensors due to their specificity. The immobilization of the enzyme is a critical step in the design of the sensor, since it is essential that the biological element exhibits maximum activity in its immobilized environment. Tang [50] proposed the modification of $\mathrm{Pt}$ electrodes with 
electrospun titanium dioxide $\left(\mathrm{TiO}_{2}\right)$ nanofibers for electrochemical detection. $\mathrm{TiO}_{2}$ nanofibers were prepared by electrospinning and deposited onto $\mathrm{Pt}$ electrodes surface. The surface of the modified electrodes was later coated with glucose oxidase (GOx). As a result, the amperometric response of the prepared enzyme electrodes indicated a higher sensitivity to glucose than those without the nanofibers. The enzyme showed good affinity to $\mathrm{TiO}_{2}$ nanofibers due to its relevant biocompatibility and higher surface area. In summary, it was essential to modify the $\mathrm{Pt}$ electrodes with an optimal density of nanofibers to obtain the maximum improvement of glucose bioelectrocatalytic properties.

Recently, novel free probe type nanoscale biosensor based on a single mesoporous Zinc Oxide $(\mathrm{ZnO}) /$ Chitosan hybrid nanostructure has been proposed by Zhao [51]. A single mesoporous $\mathrm{ZnO}$ nanofiber prepared by electrospining with subsequent annealing process was placed on the surface of the substrate electrode $\left(\mathrm{SiO}_{2} / \mathrm{Au}\right)$. The $\mathrm{GOx}$ enzymes were successfully immobilized in the $\mathrm{ZnO}$ nanofibers by electrostatic adsorption interaction and chitosan was further applied onto the electrode surface to prevent possible enzyme leakage. Thus, the prepared biosensor exhibited excellent sensitivity and fast response. The characteristic structure of mesoporous $\mathrm{ZnO}$ with pores and protuberances is favorable for enzymes loading and contributes to enhance the electrical communication efficiency. The free probe construction indicates that the single $\mathrm{ZnO} /$ Chitosan hybrid nanostructure has the potential to be further developed as a nanoprobe for trace detection in microcell and microbial monomer in in-vivo research.

As it was previously described, the immobilization of biological compounds is an essential step for biosensors since it affects the sensitivity, selectivity and long-term stability of the device. Therefore, electrospun nanofibers appear as ideal support for the immobilization of biomolecules.

\subsubsection{Energy Harvesting Systems}

Scientific progress in this area has enabled a decrease in the electrical requirements of miniaturized devices, the development of a suitable power source remains a major challenge for many devices in the bioengineering and medical fields. Harvesting energy directly from the environment is one of the most effective and promising approaches for powering such devices [44, 52-56].
The electrospun fibers opened new paths for the creation of novel, lightweight and flexible nanostructures to be used as power source systems. Our research team has proposed the development of an electrospun cellulose-based electrochemical device which can take advantage of the ionic content of the physiological fluids to generate electrical energy [22, 57]. The bio-battery proposed is composed by an ultrathin monolithic structure of an electrospun cellulose acetate membrane over which were deposited metallic thin film electrodes by thermal evaporation on both surfaces (Figure 2). In fact, the polymeric matrix has an important role since it works not only as a separator but also as the support for the electrodes. The metallic layers do not form a continuous film over the membrane surface when deposited. They cover the fibers all around instead, allowing the preservation of the main properties of the membrane (flexibility, porosity, and surface area). The concept has been proven by using a $\mathrm{Ag} /$ cellulose acetate/Al nanofiber structure which has demonstrated the ability to generate electrical energy from simulated body fluids and displayed a power density of $3 \mu \mathrm{W} . \mathrm{cm}^{-2}$ [57]. Considering that a typical power required for a pacemaker operation is around $1 \mu \mathrm{W}$, the results are quite promising. Besides the supply of low power consumption devices, biochemical monitoring systems and artificial human muscles stimulation mechanisms can also be foreseen as potential field of applications where this kind of implantable power sources are desirable [22].

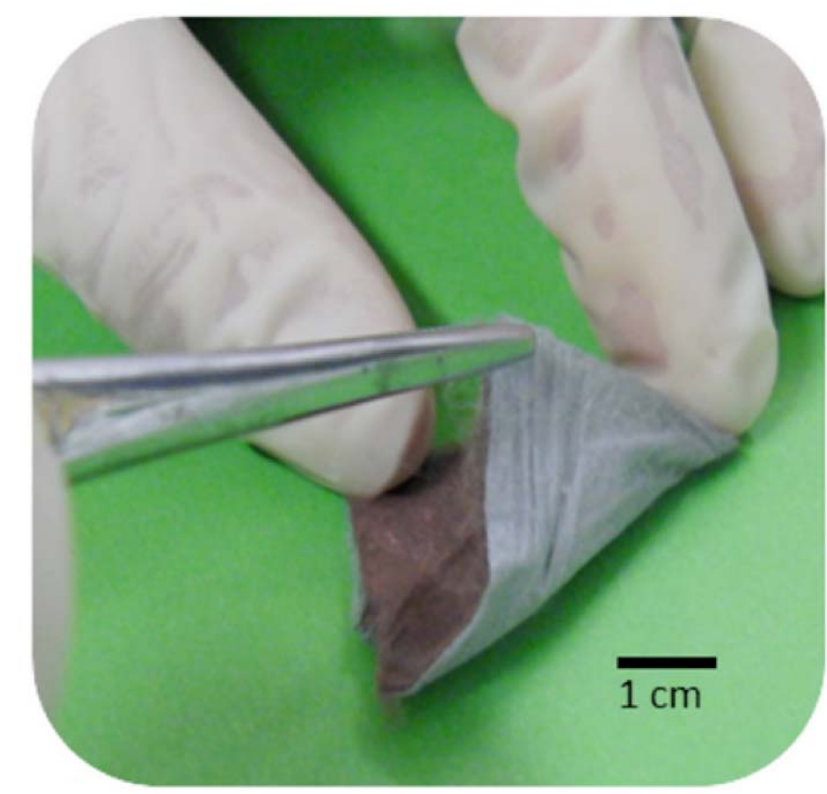

Figure 2: Bio-battery developed by our research team. It consists in a highly porous and flexible celulose-based structure over which were deposited metallic thin film electrodes. 


\section{CONCLUSIONS}

Electrospun fibers have exceptional properties, such as high specific surface area and can be easily design to have enhanced mechanical properties, biocompatibility and cellular response making them appealing to be used in composites materials in the medical field.

In tissue engineering, electrospun scaffolds made of composite materials exhibit great performance in cell attachment and proliferation. Some of the studies on tissue engineering were reviewed in this paper, such as regeneration and mimicking of blood vessels, bones and muscles. The simplicity of the electrospinning process is also suitable to incorporate therapeutic compounds into the fibers providing a useful pathway for the development of drug delivery systems. Additionally, functional electrospun nanofibers have offered opportunities to construct more efficient interfaces with electronic components with sizes comparable to those of molecules. Electronics can be made lightweight, flexible and capable of intimate, noninvasive integration with soft and curvilinear surfaces of biological tissues offering important opportunities for diagnosing and energy harvesting.

In summary, this paper reviews new insights in the development of advanced nanostructured composites materials based on electrospun fibers. From tissue engineering to bioelectronics, these composite materials can be found in the most promising research developments for biomedicine.

\section{ACKNOWLEDGEMENTS}

The authors acknowledge Portuguese Science and Technology Foundation (FCT-MCTES) for the financial support through the Strategic Project PEstC/CTM/LA0025/2013-14. Ana C. Baptista also acknowledges FCT-MCTES for the doctoral grant SFRH/BD/69306/2010.

\section{REFERENCES}

[1] Shi J, Votruba AR, Farokhzad OC and Langer $R$. Nanotechnology in drug delivery and tissue engineering: from discovery to applications. Nano Lett. 2010; 10 (9): 322330.

http://dx.doi.org/10.1021/nl102184c

[2] Jain KK. Applications of nanobiotechnology in clinical diagnostics. Clin Chem. 2007; 53 (11): 2002-9. http://dx.doi.org/10.1373/clinchem.2007.090795

[3] Baptista A, Soares P, Ferreira I and Borges JP. Nanofibers and nanoparticles in biomedical applications. In: Tiwari A, Tiwari A, editors. Bioengineered Nanomaterials USA: CRC Press (Taylor \& Francis Group); 2013
$[4]$

Harfenist SA, Cambron SD, Nelson EW, Berry SM, Isham AW, Crain MM, et al. Direct Drawing of Suspended Filamentary Micro- and Nanostructures from Liquid Polymers. Nano Lett. 2004; 4 (10): 1931-37.

http://dx.doi.org/10.1021/nl048919u

[5] Zhang Y, Lim CT, Ramakrishna S and Huang Z-M. Recent development of polymer nanofibers for biomedical and biotechnological applications. J Mater Sci-Mater M. 2005; 16: 933-46.

http://dx.doi.org/10.1007/s10856-005-4428-x

[6] Che G, Lakshmi BB, Martin CR and Fisher ER. Chemical vapor deposition based synthesis of carbon nanotubes and nanofibers using a template method. Chem Mater. 1998; 10: 260-67.

http://dx.doi.org/10.1021/cm970412f

[7] Hwang W, Kim BH, Dandu R, Cappello J, Ghandehari H and Seog J. Surface Induced nanofiber growth by self-assembly of a silk-elastin-like protein polymer. Langmuir. 2009; 25 (21): 12682-6.

http://dx.doi.org/10.1021/la9015993

[8] Ramakrishna S, Fujihara K, Teo W-E, Yong T, Ma Z and Ramaseshan $R$. Electrospun nanofibers: solving global issues. Mater Today. 2006; 9 (3): 40-50.

http://dx.doi.org/10.1016/s1369-7021(06)71389-x

[9] Yang $F$, Murugan $R$, Wang $S$ and Ramakrishna $S$. Electrospinning of nano/micro scale poly(L-lactic acid) aligned fibers and their potential in neural tissue engineering. Biomaterials. 2005; 26 (15): 2603-10. http://dx.doi.org/10.1016/..biomaterials.2004.06.051

[10] Zhuo $\mathrm{H}, \mathrm{Hu} \mathrm{J}$, Chen S and Yeung L. Preparation of polyurethane nanofibers by electrospinning. $\mathrm{J}$ of Appl Polym Sci. 2008; 109 (1): 406-11.

http://dx.doi.org/10.1002/app.28067

[11] Min B-M, Lee G, Kim SH, Nam YS, Lee TS and Park WH. Electrospinning of silk fibroin nanofibers and its effect on the adhesion and spreading of normal human keratinocytes and fibroblasts in vitro. Biomaterials. 2004; 25 (7-8): 1289-97. http://dx.doi.org/10.1016/.j.biomaterials.2003.08.045

[12] Buttafoco L, Kolkman NG, Engbers-Buijtenhuijs P, Poot AA Dijkstra PJ, Vermes I, et al. Electrospinning of collagen and elastin for tissue engineering applications. Biomaterials. 2006; 27 (5): 724-34 http://dx.doi.org/10.1016/..biomaterials.2005.06.024

[13] Canejo JP, Borges JP, Godinho MH, Brogueira P, Teixeira PIC and Terentjev EM. Helical Twisting of Electrospun Liquid Crystalline Cellulose Micro- and Nanofibers. Adv Mater. 2008; 20 (24): 4821-25. http://dx.doi.org/10.1002/adma.200801008

[14] Kim C-W, Kim D-S, Kang S-Y, Marquez M and Joo YL. Structural studies of electrospun cellulose nanofibers. Polymer. 2006; 47 (14): 5097-107.

\section{http://dx.doi.org/10.1016/j.polymer.2006.05.033}

[15] Vaz CM, van Tuijl S, Bouten CV and Baaijens FP. Design of scaffolds for blood vessel tissue engineering using a multilayering electrospinning technique. Acta Biomater. 2005; 1 (5): 575-82. http://dx.doi.org/10.1016/j.actbio.2005.06.006

[16] Franco PQ, João CFC, Silva JC and Borges JP. Electrospun hydroxyapatite fibers from a simple sol-gel system. Mater Lett. 2012; 67 (1): 233-36.

http://dx.doi.org/10.1016/j.matlet.2011.09.090

[17] Lee SJ, Tatavarty R and Gu MB. Electrospun polystyrenepoly(styrene-co-maleic anhydride) nanofiber as a new aptasensor platform. Biosens Bioelectron. 2012; 38 (1): 302http://dx.doi.org/10.1016/.j.bios.2012.06.009

[18] Miao J, Pangule RC, Paskaleva EE, Hwang EE, Kane RS Linhardt RJ, et al. Lysostaphin-functionalized cellulose fibers with antistaphylococcal activity for wound healing applications. Biomaterials. 2011; 32 (36): 9557-67. http://dx.doi.org/10.1016/..biomaterials.2011.08.080 
[19] Ji W, Sun Y, Yang F, van den Beucken JJ, Fan M, Chen Z, et al. Bioactive electrospun scaffolds delivering growth factors and genes for tissue engineering applications. Pharm Res. 2011; 28 (6): 1259-72.

http://dx.doi.org/10.1007/s11095-010-0320-6

[20] Pant HR, Pant B, Pokharel P, Kim HJ, Tijing LD, Park CH, et al. Photocatalytic TiO2-RGO/nylon-6 spider-wave-like nanonets via electrospinning and hydrothermal treatment. J Membrane Sci. 2013; 429: 225-34.

http://dx.doi.org/10.1016/j.memsci.2012.11.025

[21] Li X, Gao C, Wang J, Lu B, Chen W, Song J, et al. TiO2 films with rich bulk oxygen vacancies prepared by electrospinning for dye-sensitized solar cells. J Power Sources. 2012; 214: 244-50. http://dx.doi.org/10.1016/j.jpowsour.2012.04.042

[22] Baptista A, Ferreira I and Borges JP. Cellulose-based composite systems for biomedical applications. In: Thakur VK, Singha AS, editors. Biomass based Biocomposites. U.K.: Smithers Rapra Technology 2013. p. 47-60

[23] Agarwal S, Wendorff JH and Greiner A. Use of electrospinning technique for biomedical applications. Polymer. 2008; 49 (26): 5603-21. http://dx.doi.org/10.1016/j.polymer.2008.09.014

[24] Lee SJ, Liu J, Oh SH, Soker S, Atala A and Yoo JJ. Development of a composite vascular scaffolding system that withstands physiological vascular conditions. Biomaterials. 2008; 29 (19): 2891-8.

http://dx.doi.org/10.1016/j.biomaterials.2008.03.032

[25] Smith MJ, McClure MJ, Sell SA, Barnes CP, Walpoth BH, Simpson DG, et al. Suture-reinforced electrospun polydioxanone-elastin small-diameter tubes for use in vascular tissue engineering: a feasibility study. Acta Biomater. 2008; 4 (1): 58-66. http://dx.doi.org/10.1016/j.actbio.2007.08.001

[26] Zhang H, Jia X, Han F, Zhao J, Zhao Y, Fan Y, et al. Dualdelivery of VEGF and PDGF by double-layered electrospun membranes for blood vessel regeneration. Biomaterials. 2013; 34 (9): 2202-12.

http://dx.doi.org/10.1016/j.biomaterials.2012.12.005

[27] Prabhakaran MP, Venugopal $J$ and Ramakrishna $S$. Electrospun nanostructured scaffolds for bone tissue engineering. Acta Biomater. 2009; 5 (8): 2884-93.

http://dx.doi.org/10.1016/j.actbio.2009.05.007

[28] Ji W, Yang F, Ma J, Bouma MJ, Boerman OC, Chen Z, et al. Incorporation of stromal cell-derived factor-1alpha in PCL/gelatin electrospun membranes for guided bone regeneration. Biomaterials. 2013; 34 (3): 735-45. http://dx.doi.org/10.1016/j.biomaterials.2012.10.016

[29] Choi JS, Lee SJ, Christ GJ, Atala A and Yoo JJ. The influence of electrospun aligned poly(epsiloncaprolactone)/collagen nanofiber meshes on the formation of self-aligned skeletal muscle myotubes. Biomaterials. 2008; 29 (19): 2899-906.

http://dx.doi.org/10.1016/j.biomaterials.2008.03.031

[30] Ladd MR, Lee SJ, Stitzel JD, Atala A and Yoo JJ. Coelectrospun dual scaffolding system with potential for muscletendon junction tissue engineering. Biomaterials. 2011; 32 (6): 1549-59.

http://dx.doi.org/10.1016/j.biomaterials.2010.10.038

[31] Sell SA, McClure MJ, Garg K, Wolfe PS and Bowlin GL. Electrospinning of collagen/biopolymers for regenerative medicine and cardiovascular tissue engineering. Adv Drug Deliv Rev. 2009; 61 (12): 1007-19.

http://dx.doi.org/10.1016/j.addr.2009.07.012

[32] Dorafshar AH, Angle N, Bryer-Ash M, Huang D, Farooq MM, Gelabert HA, et al. Vascular endothelial growth factor inhibits mitogen-induced vascular smooth muscle cell proliferation. J Surg Res. 2003; 114 (2): 179-86.

http://dx.doi.org/10.1016/s0022-4804(03)00254-3
[33] Yoshikawa $Y$ and Abrahamsson S-O. Dose-related cellular effects of platelet-derived growth factor-BB differ in various types of rabbit tendons in vitro. Acta Orthop Scand. 2001; 72 (3): 287-92.

http://dx.doi.org/10.1080/00016470152846646

[34] Gentile P, Chiono V, Tonda-Turo C, Ferreira AM and Ciardelli G. Polymeric membranes for guided bone regeneration. Biotechnol J. 2011; 6 (10): 1187-97. http://dx.doi.org/10.1002/biot.201100294

[35] Fong EL, Chan CK and Goodman SB. Stem cell homing in musculoskeletal injury. Biomaterials. 2011; 32 (2): 395-409. http://dx.doi.org/10.1016/j.biomaterials.2010.08.101

[36] Liu ZJ, Zhuge $Y$ and Velazquez OC. Trafficking and differentiation of mesenchymal stem cells. J Cell Biochem. 2009; 106 (6): 984-91. http://dx.doi.org/10.1002/jcb.22091

[37] Yang PJ and Temenoff JS. Engineering Orthopedic Tissue Interfaces. Tissue Eng PT B. 2009; 15 (2): 127-41. http://dx.doi.org/10.1089=ten.teb.2008.0371

[38] Yu D-G. Electrospun nanofiber-based drug delivery systems. Health. 2009; 01 (02): 67-75. http://dx.doi.org/10.4236/health.2009.12012

[39] Choi JS, Leong KW and Yoo HS. In vivo wound healing of diabetic ulcers using electrospun nanofibers immobilized with human epidermal growth factor (EGF). Biomaterials. 2008; 29 (5): 587-96.

http://dx.doi.org/10.1016/j.biomaterials.2007.10.012

[40] Peng H, Zhou S, Guo T, Li Y, Li X, Wang J, et al. In vitro degradation and release profiles for electrospun polymeric fibers containing paracetanol. Colloids Surf B Biointerfaces. 2008; 66 (2): 206-12.

http://dx.doi.org/10.1016/j.colsurfb.2008.06.021

[41] He C-L, Huang Z-M, Han X-J, Liu L, Zhang H-S and Chen LS. Coaxial Electrospun Poly(L-Lactic Acid) Ultrafine Fibers for Sustained Drug Delivery. Journal of Macromolecular Science, Part B: Physics. 2006; 45 (4): 515-24. http://dx.doi.org/10.1080/00222340600769832

[42] Xu X, Zhuang $X$, Chen $X$, Wang $X$, Yang $L$ and Jing $X$. Preparation of Core-Sheath Composite Nanofibers by Emulsion Electrospinning. Macromol Rapid Comm. 2006; 27 (19): 1637-42.

http://dx.doi.org/10.1002/marc.200600384

[43] Wei K, Li Y, Mugishima H, Teramoto A and Abe K. Fabrication of core-sheath structured fibers for model drug release and tissue engineering by emulsion electrospinning. Biotechnol J. 2012; 7 (5): 677-85. http://dx.doi.org/10.1002/biot.201000473

[44] Baptista A, Ferreira I and Borges JB. Cellulose-based bioelectronic devices. In: van de Ven T, Godbout L, editors. Cellulose - Medical, Pharmaceutical and Electronic Applications: InTech; 2013

[45] Katz E, Buckmann AF and Willner I. Self-powered enzymebased biosensors. J Am Soc. 2001; 123: 10752-53. http://dx.doi.org/10.1021/ja0167102

[46] Tersch C and Lisdat F. Label-free detection of protein-DNA interactions using electrochemical impedance spectroscopy. Electrochimica Acta. 2011; 56 (22): 7673-79. http://dx.doi.org/10.1016/j.electacta.2011.06.063

[47] Fang X, Tan OK, Tse MS and Ooi EE. A label-free immunosensor for diagnosis of Dengue infection with simple electrical measurements. Biosens Bioelectron. 2010; 25 (5): 1137-42.

http://dx.doi.org/10.1016/j.bios.2009.09.037

[48] Osman $\mathrm{MH}$, Shah $\mathrm{AA}$ and Walsh FC. Recent progress and continuing challenges in bio-fuel cells. Part I: enzymatic cells. Biosens Bioelectron. 2011; 26 (7): 3087-102. http://dx.doi.org/10.1016/j.bios.2011.01.004 
[49] Malhotra BD and Chaubey A. Biosensors for clinical diagnostics industry. Sensors and Actuat B -Chem. 2003; 91 (1-3): 117-27. http://dx.doi.org/10.1016/s0925-4005(03)00075-3

[50] Tang H, Yan F, Tai $Q$ and Chan HL. The improvement of glucose bioelectrocatalytic properties of platinum electrodes modified with electrospun $\mathrm{TiO} 2$ nanofibers. Biosens Bioelectron. 2010; 25 (7): 1646-51. http://dx.doi.org/10.1016/j.bios.2009.11.027

[51] Zhao M, Huang J, Zhou Y, Chen Q, Pan X, He H, et al. A single mesoporous $\mathrm{ZnO} /$ Chitosan hybrid nanostructure for a novel free nanoprobe type biosensor. Biosens Bioelectron. 2013; 43: 226-30. http://dx.doi.org/10.1016/j.bios.2012.11.041

[52] Harb A. Energy harvesting: State-of-the-art. Renewable Energy. 2011; 36 (10): 2641-54. http://dx.doi.org/10.1016/j.renene.2010.06.014

[53] Bouendeu E, Greiner A, J.Smith C and Korvink JG. A LowCost Electromagnetic Generator for Vibration Energy Harvesting. IEEE Sens J. 2011; 11 (1): 107-13. http://dx.doi.org/10.1109/JSEN.2010.2050310
[54] Xu S, Qin Y, Xu C, Wei Y, Yang R and Wang ZL. Selfpowered nanowire devices. Nature Nanotechnology. 2010; 5: 366-73.

http://dx.doi.org/10.1038/nnano.2010.46

[55] Sun C, Shi J, Bayerl DJ and Wang X. PVDF microbelts for harvesting energy from respiration. Energ Environ Sci. 2011; 4 (11): 4508.

http://dx.doi.org/10.1039/c1ee02241e

[56] Bhatia D, Bairagi S, Goel S and Jangra M. Pacemakers charging using body energy. J Pharm Bioallied Sci. 2010; 2 (1): 51-4. http://dx.doi.org/10.4103/0975-7406.62713

[57] Baptista AC, Martins JI, Fortunato E, Martins R, Borges JP and Ferreira I. Thin and flexible bio-batteries made of electrospun cellulose-based membranes. Biosens Bioelectron. 2011; 26 (5): 2742-5. http://dx.doi.org/10.1016/j.bios.2010.09.055

Received on 11-11-2013

(C) 2013 Baptista et al.; Licensee Savvy Science Publisher.

This is an open access article licensed under the terms of the Creative Commons Attribution Non-Commercial License (http://creativecommons.org/licenses/by-nc/3.0/) which permits unrestricted, non-commercial use, distribution and reproduction in any medium, provided the work is properly cited. 